\title{
Serological hepatitis $A$ virus infections and ratio of clinical to serological infections in a controlled trial of pre-exposure prophylaxis with immune serum globulin
}

\author{
JEREMY D KARK, ${ }^{1}$ SHULAMITH BAR-SHANY, ${ }^{2}$ SMADAR SHOR, ${ }^{1}$ LEAH \\ MERLINSKI, ${ }^{1}$ AND ELIEZER NILI' \\ From the Medical Corps, Israel Defence Forces ${ }^{1}$ and Central Blood Bank, ${ }^{2}$ Magen David Adom, Jaffa, Israel
}

SUMMARY Seroconversion to hepatitis A virus was studied in a sub sample of 802 Israeli military recruits (611 men and 191 women) who were taking part in a randomised controlled trial of pre-exposure immune serum globulin (ISG) for the prevention of viral hepatitis. On intake into the service $35 \%$ of the men and $47 \%$ of the women were negative to hepatitis $A$ virus antibody (anti-HAV). After three years 7 of 71 men (9.9\%) who had not received pre-exposure ISG had become positive to anti-HAV compared to 2 of $83(2 \cdot 4 \%)$ who had received it; the statistical significance of this difference was $p=0.052$. At two years 2 of 30 women $(6.7 \%)$ who had not received ISG had converted compared to 1 of $43(2 \cdot 3 \%)$ who had received ISG $(p=0 \cdot 37)$. Pooling the sexes gave conversion rates of $8.9 \%$ in those not immunised and $2.4 \%$ in those immunised $(p=$ $0 \cdot 029$ ). The sex adjusted odds ratio was $4 \cdot 0$ (95\% confidence limits $1 \cdot 3-19 \cdot 0)$. The morbidity rates for clinical non B hepatitis over the three year period among 12835 men were 7.2 per 1000 in those not immunised and 3.6 per 1000 in those immunised $(p=0.004)$. Point estimates of the ratio of clinical hepatitis to seroconversion in men ranged from 0.25 to 0.30 . It is concluded that pre-exposure administration of ISG effectively prevented clinical expression of viral hepatitis, apparently reduced seroconversion, and did not induce passive-active immunisation.

Hepatitis $A$ is endemic in Israel. ${ }^{2}$ By the age of 18 , 60 to $70 \%$ of the population have antibodies to hepatitis A virus (HAV). ${ }^{3}$ Over $90 \%$ of cases of viral hepatitis in the Israel Defence Forces are non-B. Within the framework of a controlled trial of pre-exposure immune serum globulin (ISG) for prevention of non $B$ hepatitis in over 23000 male and female army recruits initiated in $1977,{ }^{4}$ a study of the serological incidence of hepatitis A was undertaken in a sample of the men and women. The objective of this report is to compare the incidence of serological HAV infection in the immunised and non-immunised groups, and to estimate the ratio of clinical to serological infection in the study population.

\section{Methods}

The characteristics of the study population that participated in a controlled trial of pre-exposure ISG prophylaxis in the Israel Defence Forces and the study design are described in a prior report. ${ }^{4}$ Briefly, in 1977,23447 recruits were allocated by service number to an intervention group and a control group of equal size. The intervention group received a $5 \mathrm{ml}$ intramuscular injection of ISG (Cutter Laboratories, USA) on the day of induction into service. HAV antibody was measured in an overlapping sample drawn the same year. Antibody to hepatitis A virus (anti-HAV) was found on intake in $80-85 \%$ of recruits of Eastern origin (father or grandfather born in North Africa or the Middle East) and in $30-40 \%$ of those of Western origin (Europe and the Americas). ${ }^{3}$ Logistic reasons and expense prevented routine laboratory examination of anti-HAV on the day of induction in all recruits. Thus ISG was administered without regard to anti-HAV status.

All cases of clinically identified hepatitis that occurred during military service were routinely and obligatorily admitted to civilian hospitals and were routinely tested for hepatitis B surface antigen. ${ }^{4}$ Men serve a compulsory period of three years and women two years. A proportion of subjects served longer than the compulsory period and a relatively smaller 
proportion served a shorter period. The cumulative incidence of clinical non B hepatitis was calculated for three years follow up in 12835 male participants in the trial. ${ }^{5}$ This slightly underestimates the actual rates due to inflation of the denominator because subjects released early were regarded as having served a full period.

On intake, a sample of trial participants randomised according to service number had blood drawn. The sera were stored at $-20 \mathrm{C}$. On the day of release from service an effort was made to reascertain this sample and draw a second blood specimen. Men were ascertained on release from three to four years' service and women after two to three years' service. Subjects released from duty before completing their compulsory service period or those who served more than an additional year were not sought. Examination of the sample who had blood drawn on recruitment showed that service duration was equally distributed between the trial groups.

There was a higher proportion of immunised than non-immunised participants among those contacted on discharge from service $(53 \% v 47 \%)$. The blood drawing team appears to have missed more participants with service number combinations ending in odd digits, the non-immunised, than those with even digits, the immunised, who were routinely sought for other purposes. The relative underascertainment of the non-immunised group was greater in men and women who served for longer than their compulsory period. This could increase the possibility of bias in the comparison of seroconversion proportions in the trial groups.
Therefore serological data were analysed separately for releases who served their normal compulsory period and for the complete follow up population which included also those who served up to an additional year.

HAV antibodies were quantified by solid phase radioimmunoassay (HAVAB $^{\mathrm{Tm}}$ Kits, Abbott Laboratories), first for the sera drawn on induction into service and, subsequently, for the second serum sample in subjects who were HAV negative on intake. Antibody levels were dichotomised into absent or present. Paired sera of all seroconverters were re-examined to ensure correct classification.

Statistical testing for the difference in seroconversion between the trial groups was by a one-tailed Fisher's exact test. Confidence limits for proportions were calculated by an exact binomial method. ${ }^{6}$ The Cornfield-Gart method $^{7}$ was used to control for sex in analysis of the serological data. Confidence limits for the clinical to seroconversion ratio were calculated as in Kleinbaum, Kupper and Morgenstern. ${ }^{8}$

\section{Results}

\section{SEROLOGICAL RESULTS}

Table 1 shows the distribution of subjects in the serological study who received ISG and those whot did not. At recruitment 1014 sera were taken from men and 674 from women. These were nearly equally distributed between immunised and non-immunised. On discharge from service we contacted 701 men $(69 \%)$ and 207 women (31\%). Of these, 41 men and

Table 1 Number of sera taken at recruitment and at discharge and number and proportion of paired sera that were anti $H A V$ negative at recruitment separately by sex and immunisation group for all subjects and for those who served no more than their normal compulsory service period

\begin{tabular}{|c|c|c|c|c|c|c|c|c|c|}
\hline \multirow{3}{*}{$\begin{array}{l}\text { Sex and } \\
\text { immunisation }\end{array}$} & \multirow{3}{*}{$\begin{array}{l}\text { Sera at } \\
\text { recruitment }\end{array}$} & \multicolumn{5}{|c|}{ All study subjects } & \multicolumn{3}{|c|}{ Compulsory service only } \\
\hline & & \multicolumn{2}{|c|}{$\begin{array}{l}\text { Contacted } \\
\text { at discharge }\end{array}$} & \multirow{2}{*}{$\begin{array}{l}\text { Paired sera } \\
\text { at discharge }\end{array}$} & \multirow{2}{*}{$\begin{array}{l}\text { Number } \\
\text { seronegative }\end{array}$} & \multirow{2}{*}{$\begin{array}{l}\text { Proportion } \\
\text { seronegative }\end{array}$} & \multirow{2}{*}{$\begin{array}{l}\text { Paired sera } \\
\text { at discharge }\end{array}$} & \multirow{2}{*}{$\begin{array}{l}\text { Number } \\
\text { seronegative }\end{array}$} & \multirow{2}{*}{$\begin{array}{l}\text { Proportion } \\
\text { seronegative }\end{array}$} \\
\hline & & $N$ & $\%$ & & & & & & \\
\hline \multicolumn{10}{|l|}{ Men } \\
\hline Not immunised & 496 & 329 & 66 & 279 & 95 & 0.34 & 212 & 71 & 0.33 \\
\hline Immunised & 518 & 372 & 72 & 332 & 119 & 0.36 & 240 & 83 & 0.35 \\
\hline All & 1014 & 701 & 69 & 611 & 214 & $0 \cdot 35$ & 452 & 154 & $0 \cdot 34$ \\
\hline \multicolumn{10}{|l|}{ Women } \\
\hline Not immunised & 332 & 94 & 28 & 89 & 34 & 0.38 & 76 & 30 & 0.39 \\
\hline Immunised & 342 & 113 & 33 & 102 & 55 & 0.54 & 77 & 43 & 0.56 \\
\hline All & 674 & 207 & 31 & 191 & 89 & $0 \cdot 47$ & 153 & 73 & 0.48 \\
\hline \multicolumn{10}{|l|}{ Persons } \\
\hline Not immunised & 828 & 423 & 51 & 368 & 129 & 0.35 & 288 & 101 & 0.35 \\
\hline Immunised & 860 & 485 & 56 & 434 & 174 & 0.40 & 317 & 126 & $0 \cdot 40$ \\
\hline All persons & 1688 & 908 & 54 & 802 & 303 & 0.38 & 605 & 227 & $0 \cdot 38$ \\
\hline
\end{tabular}


11 women refused to participate, and 49 men and 5 women did not have available stored samples of sera that had been drawn at recruitment. Thus paired sera were available for 611 men $(60 \%)$ and $191(28 \%)$ women. Reasons for loss to follow up in men were early discharge from service, service of more than four years' duration, and non-ascertainment by the blood drawing team on the day of release (see Methods). The low catchment of women was largely because we started the paired sera study when most of them had been discharged after 24 months' service.

There was a total of 214 men and 89 women with paired sera who had been HAV antibody negative at recruitment, and of those who completed no more than their compulsory service 154 men and 73 women had been negative. As seen in Table 1, the proportion of initially seronegative men in those with paired sera was similar in the two trial groups, whereas in women with paired sera there was a higher proportion of seronegatives among the immunised group $(p=0.042)$.

These subjects who had been HAV antibody negative were the only ones who might have benefited from immunisation, and they are now analysed in further detail to ascertain conversion rates.

Table 2 shows the number of subjects who converted from HAV antibody negative during their service. Of the total 303 subjects negative at recruitment who had paired sera, $17(5 \cdot 6 \%)$ had seroconverted at discharge. But within the immunised and non-immunised groups only 6 out of
$174(3.4 \%)$ immunised subjects converted whereas 11 out of $129(8 \cdot 5 \%)$ non-immunised converted $(\mathrm{p}=$ $0.050)$. The sex adjusted odds ratio was 2.5 with $95 \%$ confidence limits ranging from 0.8 to $8 \cdot 0$. In the 227 initially seronegative subjects discharged after no more than normal service the seroconversion rate was $8.9 \%$ in the immunised group and $2.4 \%$ in the non-immunised $(p=0.029)$. The sex adjusted odds ratio was 4.0 (95\% confidence limits 1.3 to $19 \cdot 0)$.

For both men and women the non-immunised groups experienced two to fourfold more seroconversion than the immunised groups. For men discharged after normal service the difference was of borderline statistical significance $(p=0.052)$, while for both sexes together the $95 \%$ confidence limits of the adjusted odds ratio excluded unity. Differences between the trial groups were somewhat smaller and less significant for the total follow up.

Possible confounding factors considered were ethnic origin ${ }^{3}$ and army classification score. ${ }^{9}$ The classification score determines placement and roles of personnel in service and hence may be considered an indicator of exposure to infection, while ethnicity reflects attributes that may be associated with both exposure and susceptibility. The distribution of these variables in the two trial groups and the overall seroconversion proportions in the two main origin groups (Europe and Asia-North Africa) were sufficiently similar to rule out confounding by these factors as an explanation for the findings.

An ethnic stratified analysis showed, however, that the association was confined to the European origin group in both sexes and was statistically significant ( $p$

Table 2 Status at discharge of persons negative to anti HAV at recruitment by sex and immunisation group showing the conversion rates and odds ratio for all subjects and those with no more than normal service duration

\begin{tabular}{|c|c|c|c|c|c|c|c|c|}
\hline \multirow[b]{2}{*}{$\begin{array}{l}\text { Sex and } \\
\text { immunisation }\end{array}$} & \multicolumn{4}{|c|}{ All discharges } & \multicolumn{4}{|c|}{ Normal service only } \\
\hline & Positive & Negative & $\begin{array}{l}\text { Proportion of } \\
\text { seroconverters }\end{array}$ & $P$ value & Positive & Negative & $\begin{array}{l}\text { Proportion of } \\
\text { seroconverters }\end{array}$ & $P$ value \\
\hline \multicolumn{9}{|l|}{ Men } \\
\hline $\begin{array}{l}\text { Not immunised } \\
\text { Immunised }\end{array}$ & $\begin{array}{l}9 \\
5\end{array}$ & $\begin{array}{r}86 \\
114\end{array}$ & $\begin{array}{l}0.095 \\
0.042\end{array}$ & 0.102 & $\begin{array}{l}7 \\
2\end{array}$ & $\begin{array}{l}64 \\
81\end{array}$ & $\begin{array}{l}0.099 \\
0.024\end{array}$ & 0.052 \\
\hline Odds ratio & \multicolumn{2}{|c|}{$2 \cdot 4$} & & & \multicolumn{2}{|c|}{$4 \cdot 4$} & & \\
\hline \multicolumn{9}{|l|}{ Women } \\
\hline $\begin{array}{l}\text { Not immunised } \\
\text { Immunised }\end{array}$ & $\begin{array}{l}2 \\
1\end{array}$ & $\begin{array}{l}32 \\
54\end{array}$ & $\begin{array}{l}0.059 \\
0.018\end{array}$ & $0 \cdot 32$ & $\begin{array}{l}2 \\
1\end{array}$ & $\begin{array}{l}28 \\
42\end{array}$ & $\begin{array}{l}0.067 \\
0.023\end{array}$ & $0 \cdot 37$ \\
\hline Odds ratio & \multicolumn{2}{|c|}{$3 \cdot 4$} & & & \multicolumn{2}{|c|}{$3 \cdot 0$} & & \\
\hline \multicolumn{9}{|l|}{ Persons } \\
\hline $\begin{array}{l}\text { Not immunised } \\
\text { Immunised }\end{array}$ & $\begin{array}{r}11 \\
6\end{array}$ & $\begin{array}{l}118 \\
168\end{array}$ & $\begin{array}{l}0.085 \\
0.034\end{array}$ & 0.050 & $\begin{array}{l}9 \\
3\end{array}$ & $\begin{array}{r}92 \\
123\end{array}$ & $\begin{array}{l}0.089 \\
0.024\end{array}$ & 0.029 \\
\hline $\begin{array}{l}\text { Odds ratio } \\
\text { Sex adjusted } \\
95 \% \text { confidence }\end{array}$ & \multicolumn{3}{|c|}{$2 \cdot 6$} & & \multicolumn{2}{|c|}{$4 \cdot 0$} & & \\
\hline $\begin{array}{l}\text { limits of odds } \\
\text { ratio }\end{array}$ & \multicolumn{2}{|c|}{0.8 to 8.0} & & & \multicolumn{2}{|c|}{$1 \cdot 3$ to $19 \cdot 0$} & & \\
\hline
\end{tabular}


$=0.025$ for the sex-pooled data for the compulsory service period and $\mathrm{p}=0.006$ for the whole follow up). This origin group represented over two thirds of the study population. In the smaller group of North African and Asian origin no association was evident for the normal service period, and there was a statistically non-significant inverse association $(\mathrm{p}=$ $0 \cdot 43$ ) when the additional follow up was included.

\section{CLINICAL RESULTS}

Of the 17 subjects who converted at the time of discharge five had had clinically diagnosed HBsAg negative hepatitis during their service, four men and one woman. The proportion of converters who had overt hepatitis was 0.29 (exact binomial 95\% confidence limits $0 \cdot 10$ to $0 \cdot 56$ ).

A second approach was also used to estimate the ratio of clinically manifest infections to serological infections. Table 3 shows clinical morbidity data from the cohort of 12835 male trial participants followed up for three years. Women were not analysed by this method. The three year cumulative incidence of HBsAg negative hepatitis among 6417 men not immunised was $46(7.2$ per 1000) and among 6418 men allocated to immunisation was 23 (3.6 per 1000). ${ }^{5}$ The statistical significance of this difference using Fisher's exact test was $p=0.004$. On the assumption that $35 \%$ of the total male population was seronegative at recruitment and that all clinical cases of non B hepatitis occurred in these negative subjects then the three year cumulative incidence becomes 20.5 per 1000 in the non-immunised and $10 \cdot 2$ per 1000 in the immunised. The ratio of the clinical infection rate in the susceptibles to the three year seroconversion rate was $0 \cdot 26(95 \%$ confidence limits 0.13 to 0.52 ). When the seroconversion rate from the total follow up sample was used the ratio became $0 \cdot 24$.

Table 3 Proportion of clinical hepatitis over three years in male recruits by immunisation groups with estimates of proportion of susceptibles only and ratio of clinical manifestation to seroconversion

\begin{tabular}{lccc}
\hline & \multicolumn{3}{l}{$\begin{array}{l}\text { Not } \\
\text { Immunised }\end{array}$} \\
& immunised & All men \\
\hline Clinical hepatitis/1000 & 3.6 & 7.2 & 5.4 \\
Clinical hepatitis in susceptibles/1000 & 10.2 & 20.5 & 15.4 \\
Seroconversion in negatives/1000 & 24.0 & 99.0 & 58.4 \\
Ratio of clinical incidence & 0.42 & 0.21 & 0.26 \\
$\begin{array}{l}\text { to seroconversion } \\
95 \% \text { Confidence limits }\end{array}$ & & & 0.13 to 0.52 \\
\hline
\end{tabular}

Thus both methods give similar estimates of the proportion of serological conversions that were observed as clinical hepatitis although the $95 \%$ confidence limits of this estimate are wide.

The data were too small to give separate estimates of the ratio of clinical cases to seroconversion for the intervention and control groups.

\section{Discussion}

The difference in the incidence rates of $\overrightarrow{\vec{\rho}}$ seroconversion among the immunised and 0 non-immunised groups suggests that the HAV $\frac{0}{\bar{N}}$ antibody content of the ISG in the dose administered $\frac{\bar{\omega}}{\frac{\sigma}{\sigma}}$ on intake, which unfortunately we did not measure in $\mathbb{\Phi}$ this study, suppressed seroconversion, possibly by neutralisation of infective doses of virus as proposed by Mosley. ${ }^{10} \mathrm{It}$ is noteworthy that this difference was identifiable in men three years after receipt of ISG in $\overrightarrow{\vec{\omega}}$ the trial although the effect in terms of risk ratios $\stackrel{\sigma}{\omega}$ would be expected to be 'diluted' by infection $\bar{\varnothing}$ occurring in both trial groups after protection ? subsided. The detailed clinical morbidity data reported elsewhere ${ }^{j}$ suggest that ISG may provide्E some protection for more than 6-9 months. The on $\overrightarrow{\vec{A}}$ initial difference between the two trial groups (those allocated to receive ISG and those not) lay in the $\frac{\mathbb{Q}}{\square}$ immunisation status at induction. Many werc subsequently immunised annually during theg service, some up to three times. The allocatiog $ه$ procedure in this trial and the large sample size $\overrightarrow{0}$ should assure that subsequent immunisations with or ISG during the follow up period, exposure to virus during service, and susceptibility to disease were equally distributed in the two trial groups. In our sample of seronegative subjects, the findings could not be attributed to confounding by ethnicity or by $\stackrel{\odot}{\mathcal{Q}}$ the army classification score. Therefore, the difference in seroconversion rates probably reflects $\overrightarrow{0}$ either the effect of the initial ISG immunisation or a chance finding which could occur three to five times in a hundred with the sample size examined here. However, the possibility of an unidentified bias resulting from loss to follow up and unequal ? ascertainment of serological samples in the two trial groups cannot be excluded. The findings were confined to the European origin group while no 0 association was evident in the smaller Asian-North $₹$ African group. We can advance no explanation other 윽 than chance for this apparent interaction.

The incidence of seroconversion over three years in the non-immunised men $(10 \%, 95 \%$ confidence $N$ limits 4 to $19 \%$ ) was lower than expected in light of $\%$ the high incidence of faecal-oral infections in the $\tilde{N}$ Israeli Defence Forces. We suggest that the extensive $\underset{\omega}{N}$ use of ISG in the Israeli Defence Forces substantially 
reduces transmission of virus and hence results in fewer HAV infections in both the immunised and non-immunised. We have presented evidence consistent with a herd immunity effect ${ }^{411}$ that could result from reduced viral transmission. Mosley ${ }^{10}$ states that ISG tends to reduce the amount of virus excreted in infected persons. We estimate that between one third and a half of our study population received repeated annual injections of ISG which would also have inhibited virus transmission, infection, and hence seroconversion.

Although the serological data are based on relatively small numbers of seroconversion, there is evidence that ISG suppressed both clinical and serological expressions of infection. In this study population, the ratio of seroconversion to clinical morbidity was about 3:1. Clinically inapparent serological infections are associated with less viral excretion than clinical disease..$^{12-14}$ thus from the viewpoint of virus transmission, subclinical cases, which appear to predominate in our population, represent a lesser risk for transmission of virus than the clinical infections.

The study sample was too small to detect statistically significant differences in the proportion of clinical to serological expressions of infection in the immunised and non-immunised, if they do indeed exist. Nevertheless, if ISG suppressed clinical manifestations but not serological expressions of infection then the clinical to serological ratio in the immunised group should have been about half that in the non-immunised. This was not the case. This concurs with the findings of Mosley, who suggested that subclinical seroconversion after pre-exposure ISG occurs infrequently and less commonly than was previously thought. ${ }^{10}$

Suppression of seroconversion by ISG was inferred from two uncontrolled studies of Swedish United Nations forces in Cyprus, ${ }^{15}$ and in the Sinai, ${ }^{16}$ where little or no seroconversion occurred. Our controlled data lead to a similar conclusion. The ratio of subclinical to clinical cases in the Swedish data was $3: 4 .{ }^{17}$ In institutionalised children and the staff in a study in the United States, ${ }^{18}$ ISG appeared to induce complete passive protection more commonly than passive-active immunity. The subclinical to clinical ratios were about $1: 1$ in both children and staff. A large scale US Army trial of pre-exposure ISG in south east Asia was also interpreted as showing no evidence for passive-active protection. ${ }^{19}$

In a study of HAV infections in households in Costa Rica, a hyperendemic area for hepatitis $\mathbf{A}^{20}$ most infections in adults over the age of 20 were inapparent. Of considerable interest was the observation that an immunoglobulin $\mathbf{M}$ response was absent in a progressively larger proportion of inapparent infections, ranging from $20 \%$ in the 5-9 year age group to $97 \%$ in those aged $20+$. The authors suggest that this finding indicates restimulation of immunoglobulin $\mathbf{G}$ antibodies by reinfection. Had a similar phenomenon occurred in the current study, i.e. that a portion of the seroconversions were indeed reinfections, then the seroconversion rate and hence the ratio of seroconversion to clinical disease in previously uninfected people could be overestimated.

ISG appears to suppress seroconversion, an effect that may be viewed as negative because HAV infected subjects do not develop protective antibody and thus remain susceptible to subsequent infection when the protective ISG effect wears off. However, this effect of ISG administration at intake in our population is of little public health significance because about $90 \%$ of the initially susceptible, non-immunised participants versus more than $95 \%$ of the immunised recruits remained seronegative over three years' follow up-a trivial difference from the viewpoint of population susceptibility to future infection. ISG given on the day of recruitment into military service was a highly effective preventive measure and was preferable to the policy of post-exposure prophylaxis that prevailed before this trial.

\section{References}

${ }^{1}$ Eliakim M. Epidemiology of viral hepatitis in Israel, 1978. Isr J Med Sci 1979; 147: 714-9.

${ }^{2}$ Bar-Shany S, Naggan L, Szmuness W. Prevalence of antibodies to hepatitis: Anti-HA and anti-HBs. Harefuah 1977; 93: 390-2.

${ }^{3}$ Kark JD, Bar-Shany S. Hepatitis A antibody in Israel Defence Forces recruits. J Med Virol 1980; 6: 341-5.

${ }^{4} \mathrm{Kark}$ JD. Pre-exposure prophylaxis with immune serum globulin for prevention of viral hepatitis in a population of army recruits. J Epidemiol Comm Hlth 1982; 36: 176-82.

${ }^{5}$ Kark JD, Witztum E, Mazkin H, Nili E, Danon Y. The three year incidence of non B viral hepatitis morbidity in a controlled trial of pre-exposure immune serum globulin prophylaxis. Infection 1984; 12: 251-5.

- Abramson JH, Peritz E. Calculator programs for the health science. New York: Oxford University Press 1983.

${ }^{7}$ Fleiss JL. Statistical methods for rates and proportions. New York: John Wiley 1981; 2nd ed: 168-173.

${ }^{8}$ Kleinbaum DG, Kupper LL, Morgenstern $\mathbf{H}$. Epidemiologic research. Belmont, California: Lifetime Learning Publications 1982; 297-9.

${ }^{9}$ Amir Y, Kovarsky Y, Sharan S. Peer nominations as a predictor of multistage promotions in a ramified organization. J Applied Psych 1970; 54: 462-9.

${ }^{10}$ Mosley JW. Epidemiology of HAV infection. In: Vyas $\mathrm{GN}$, Cohen $\mathrm{SN}$, Schmid $\mathrm{R}$, eds. Viral hepatitis. Philadelphia: Franklin Institute Press 1978; 85-104. 
${ }^{11}$ Kark JD: Pre-exposure prophylaxis of viral hepatitis with immune serum globulin in an endemic area. A trial in field units of the Israel Defence Forces. Scand $J$ Infect Dis 1983; 15: 3-6.

${ }^{12}$ Frösner GG, Overby LR, Flehmig B, Gerth HJ, Haas H, Decker RH, Ling CM, Zuckerman AJ, Frösner HR. Seroepidemiological investigations of patients and family contacts in an epidemic of hepatitis A. J Med Virol 1977; 1: 163-73.

${ }^{13}$ Routenberg JA, Dienstag JL, Harrison WO, Kilpatrick ME, Hooper RR, Chisari FW, Purcell RH, Fornes MF. Foodborne outbreak of hepatitis A: Clinical and laboratory features of acute and protracted illness. Am J Med Sci 1979; 278: 123-37.

${ }^{14}$ Coulepis AG, Locarnini SA, Lehmann NI, Gust ID. Detection of hepatitis A virus in the feces of patients with naturally acquired infections. J Infect Dis 1980; 141: $151-6$.

${ }^{15}$ Weiland O, Berg JVR, Back E, Lundbergh P. Immunoglobulin prophylaxis against hepatitis $A$ among Swedish UN soldiers in an endemic region. Infection 1979; 7: 223-5.

${ }^{16}$ Weiland $\mathrm{O}$, Niklasson B, Berg R, Lundbergh $\mathbf{P}$, Tidestrom L. Clinical and subclinical hepatitis A occurring after immunoglobulin prophylaxis among Swedish UN soldiers in Sinai. Scand $J$ Gastoenterol 1981; 16: 967-72.
${ }^{17}$ Weiland O. Hepatitis A. Aspects on prophylaxis and a comparison with hepatitis B and hepatitis Non-A, Non-B on epidemiology and prognosis. Scand J Infect Dis 1981; 28: (Suppl) 1-73.

${ }^{18}$ Rakela J, Nugent E, Mosley JW. Viral hepatitis: enzyme assays and serologic procedures in the study of an epidemic. Am J Epidemiol 1977; 106: 493-501.

${ }^{19}$ Cooperative Study. Prophylactic gamma globulin for prevention of endemic hepatitis: Effects of US gamma globulin upon the incidence of viral hepatitis and other infectious diseases in US soldiers abroad. Arch Intern Med 1971; 128: 723-38.

${ }^{20}$ Villarejos VM, Serra CJ, Anderson-Visona K, Mosley JW. Hepatitis A virus infection in households. $A m J$ Epidemiol 1982; 115: 577-86.

Address for correspondence: Dr J D Kark, Department of Social Medicine, Hebrew University-Hadassah School of Public Health and Community Medicine and Hadassah Medical Organization, Ein Karem, Jerusalem, Israel. 